\title{
Intake of game birds in the UK: assessment of the contribution to the dietary intake of lead by women of childbearing age and children
}

\author{
Caroline M Taylor*, Jean Golding and Alan M Emond
}

Centre for Child and Adolescent Health, School of Social and Community Medicine, University of Bristol, Oakfield House, Oakfield Grove, Bristol BS8 2BN, UK

Submitted 15 0ctober 2012: Final revision received 11 February 2013: Accepted 12 February 2013: First published online 26 March 2013

\begin{abstract}
Objective: Concern has recently been expressed about $\mathrm{Pb}$ levels in $\mathrm{Pb}$-shot game meat. Our aim was to determine the consumption of game birds in a representative sample population in the UK, and in children and women of childbearing age in particular.

Design: Population-based cross-sectional cohort study. Data from $4 \mathrm{~d}$ diet diaries from the UK National Diet and Nutrition Survey (NDNS; 2008-2010) were extracted to analyse data on game bird consumption in the sample population, in women of childbearing age (15-45 years old) and in children $\leq 6$ years old.

Setting: Home-based study in representative areas of the UK.

Subjects: Participants in the NDNS (2008-2010; $n$ 2126, age 1.5 to $>65$ years).

Results: Fifty-eight participants $(2 \cdot 7 \%)$ reported eating game birds. The mean intake was $19 \cdot 5$ (SD 18.1) g/d (median 15.6, range $1.3-92 \cdot 9 \mathrm{~g} / \mathrm{d}$ ). In women of childbearing age (15-45 years), 11/383 (2.9\%) reported eating game birds, with a mean intake of $22 \cdot 4(\mathrm{SD} 25 \cdot 8) \mathrm{g} / \mathrm{d}$ (median $15 \cdot 6$, range $2 \cdot 0-92 \cdot 9 \mathrm{~g} / \mathrm{d}$ ). In children aged $\leq 6$ years old, $3 / 342(0.9 \%)$ were reported as eating game birds, with a mean intake of $6 \cdot 8(\mathrm{sD} 9 \cdot 7) \mathrm{g} / \mathrm{d}$ (median $2 \cdot 4$, range $1 \cdot 3-23 \cdot 2 \mathrm{~g} / \mathrm{d}$ ).

Conclusions: The prevalence of consumption of game birds by women of childbearing age and children $\leq 6$ years old was relatively low and intakes were small. However, any exposure to $\mathrm{Pb}$ in these two groups is undesirable. As are uncertainties about the ability of the diet diary method to capture the consumption of food items that are infrequently consumed, alternative methods of capturing these data should be used in future studies.
\end{abstract}

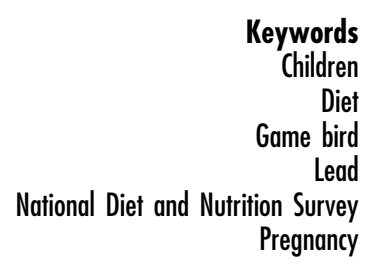

eywords

bird

Lead

Pregnancy
$\mathrm{Pb}$ is a neurotoxic non-essential metal that is widespread in the environment. Bans on $\mathrm{Pb}$ in petrol, paint and food cans, and replacement of $\mathrm{Pb}$ water pipes, have led to a decline in blood $\mathrm{Pb}$ levels in the $\mathrm{UK}^{(1)}$, so that diet is now thought to be the main contributor to exposure to $\mathrm{Pb}$ in the European Union ${ }^{(2)}$.

$\mathrm{Pb}$ bullets and $\mathrm{Pb}$ gunshot fragment on impact, leading to high $\mathrm{Pb}$ levels in the resulting game meat (exceeding the European Union maximum limit for other types of meat) ${ }^{(3)}$, and it is known that frequent game consumption is associated with higher blood $\mathrm{Pb}$ levels in hunting communities $^{(4,5)}$. Game is increasingly being promoted as a healthy and ethical choice ${ }^{(6)}$ and is increasingly available in supermarkets ${ }^{(7)}$; however, there is concern that an increase in the consumption of game killed with $\mathrm{Pb}$ shot or bullets may have a detrimental effect on blood $\mathrm{Pb}$ levels and associated health outcomes, including intelligence quotient and educational measures in children, miscarriage in pregnant women, and chronic kidney disease and increased blood pressure in adults ${ }^{(8)}$.

$\mathrm{Pb}$ is transferred freely to the fetus through the placenta; as the fetus and growing child are especially sensitive to the neurotoxic effects of $\mathrm{Pb}$, pregnant women and young children are particularly vulnerable. The Food Standards Agency in the UK has recently recommended that pregnant women, women planning to become pregnant, and toddlers and children should avoid eating Pb-shot game ${ }^{(9)}$. Germany and Spain offer similar advice, but are more specific about the age of the children $(<6 \text { and }<7 \text { years, respectively })^{(10,11)}$. All three countries also advise people who are frequent consumers of game to reduce their consumption. To assess the extent of any 
potential problem at a population level, it is necessary to have up-to-date data on game consumption: to our knowledge there are no recent data available on game consumption in children and pregnant women in the UK. Our aim was to use the most recently available UK National Diet and Nutrition Survey (NDNS; 2008-2010) ${ }^{(12)}$ to determine the consumption of game birds by children and women of childbearing age, as well as in the sample as a whole, and to identify any factors that might be associated with the consumption of game birds.

\section{Methods}

\section{The National Diet and Nutrition Survey}

The NDNS is a survey of the food consumption, nutrient intakes and nutritional status of people aged $\geq 1.5$ years in private households in the UK. The survey is carried out in all four countries of the UK and is designed to be representative of the UK population. The survey has been described in detail elsewhere ${ }^{(13)}$.

In brief, the study sample was randomly drawn from the postcode address file, which is a list of all the addresses in the UK. The addresses were clustered into primary sampling units (small geographical areas based on postcode sectors, randomly selected from across the UK). A core sample of 3510 addresses was selected from 130 primary sampling units. Twenty-seven addresses were randomly selected from each primary sampling unit. At each address, an interviewer established the number of households, and in cases where there were two or more, the interviewer selected one household at random. The twenty-seven addresses were randomly allocated to one of two groups: adult and child, if present ( $n$ 9), and child only ( $n$ 18). Information describing the purpose of the study was sent to all selected addresses by post. This was followed by a face-to-face visit by an interviewer to each address to recruit participants in the eligible age range. From the core sample of 3510 addresses, 1031 adults and 1095 children provided complete data including diet diaries.

\section{Interviews and questionnaires}

The interview and questionnaire methods have been described in detail elsewhere ${ }^{(14)}$. In brief, each participant had a face-to-face computer-assisted personal interview (for children, the interview was with the parent/guardian). The interviewer collected information on demographic variables such as the age and sex of participants, educational attainment, housing tenure and shopping habits (type of shop used, buying organic meat, etc.) and region of residence based on Government Office Regions created by the UK government for administrative purposes.

\section{Diet diaries}

The participants prospectively completed a $4 \mathrm{~d}$ diet diary after being given detailed instructions. The parent/carer was asked to complete the diary for children aged 11 years or younger, with help from the child as appropriate. Children aged 12 years and older were asked to complete the diary themselves, but the details were confirmed with their parent/carer as necessary. The participants were asked to describe the quantity or portion size of each food item using household measures, weights from labels, the number of items or picture items that were supplied in the diet diary. After completion, the diary was checked by the interviewer for completeness of information; participants were asked for further information if necessary. Analysis of the diet diaries was carried out as previously described ${ }^{(13)}$.

\section{Etbics approval}

The study was conducted according to the guidelines laid down in the Declaration of Helsinki and all procedures involving human subjects were approved by the Oxfordshire A Research Ethics Committee. Informed consent was obtained from all participants.

\section{Data}

Data files were obtained from the Economic and Social Data Service $^{(12)}$ and relevant variables were extracted. In addition to data on game bird consumption and total meat intakes obtained from $4 \mathrm{~d}$ diet diaries, additional data extracted on demographic variables included the age and sex of participants, educational attainment, housing tenure and shopping habits (type of shop used, buying organic meat, etc.) and region of residence.

The data were used to calculate number of participants who reported eating game birds in the $4 \mathrm{~d}$ diet diary. Mean portion sizes for game bird consumers were calculated and this was further examined by age (age groups of $\leq 6,6-18,19-64$ and $\geq 65$ years). The prevalence of consumption was also calculated by region of residence to identify parts of the country that might have relatively high consumption of game birds. The effect of the shooting season on game bird consumption was examined by calculating the prevalence of consumption in August to February (encompasses shooting seasons for grouse, pheasant, partridge, ptarmigan and black game in the UK) compared with the prevalence in March to July (out of season for game birds in the UK).

\section{Statistical analysis}

A weighting factor adjustment was used to correct for known sociodemographic differences between the composition of the survey sample and the total population of the UK (age by sex and Government Office Region) ${ }^{(15)}$. This takes account of bias due to non-response and the difference in the probability of households and individuals being selected to take part. Data analysis was carried out using the statistical software package SPSS version 18 . The $\chi^{2}$ test and ANOVA were used to analyse continuous and categorical data, respectively. A $P$ value $<0.05$ was considered to be statistically significant. 
Table 1 Prevalence of game bird consumption, portion size and proportion of total meat intake in the UK (NDNS 2008-2010; $n$ 2126, participants aged 1.5 to $>65$ years)

\begin{tabular}{|c|c|c|c|c|c|c|c|c|c|c|}
\hline \multirow[b]{3}{*}{ Age (years) } & \multicolumn{4}{|c|}{ Eat game birds* } & \multirow{2}{*}{\multicolumn{3}{|c|}{ Game bird consumption if yes $(\mathrm{g} / \mathrm{d}) \dagger$}} & \multirow{2}{*}{\multicolumn{3}{|c|}{$\begin{array}{l}\text { Game bird meat as proportion of total } \\
\text { meat intake for game bird consumers }\end{array}$}} \\
\hline & \multicolumn{2}{|c|}{ Yes } & \multicolumn{2}{|c|}{ No } & & & & & & \\
\hline & $n$ & $\%$ & $n$ & $\%$ & Mean & SD & Range & Mean & SD & Range \\
\hline$\leq 6$ & 3 & $5 \cdot 2$ & 339 & $16 \cdot 4$ & $6 \cdot 8$ & $9 \cdot 7$ & $1 \cdot 3-23 \cdot 2$ & 0.08 & $0 \cdot 11$ & $0.01-0.26$ \\
\hline $6-18$ & 15 & $25 \cdot 9$ & 737 & $35 \cdot 7$ & $22 \cdot 3$ & 21.9 & $3 \cdot 75-92 \cdot 9$ & $0 \cdot 19$ & $0 \cdot 19$ & $0.06-0.76$ \\
\hline $19-64$ & 34 & $58 \cdot 9$ & 779 & $37 \cdot 7$ & $17 \cdot 8$ & $13 \cdot 4$ & $2 \cdot 0-46 \cdot 9$ & $0 \cdot 18$ & $0 \cdot 16$ & $0.02-0.54$ \\
\hline$\geq 65$ & 6 & $10 \cdot 3$ & 212 & $10 \cdot 3$ & $30 \cdot 1$ & $30 \cdot 1$ & $1 \cdot 8-79 \cdot 0$ & 0.28 & 0.29 & $0.00-0.76$ \\
\hline
\end{tabular}

NDNS, National Diet and Nutrition Survey.

${ }^{*} \chi^{2}$ test for effect of age group on game bird consumption (yes/no), $P=0.006$.

tANOVA for effect of age group on intake of game birds in game bird consumers, $P=0.224$ (NS).

‡ANOVA for effect of age group on game birds as a proportion of total meat intake in game bird consumers, $P=0.406$ (NS).

\section{Results}

\section{Four-day diet diary}

Of the 2126 participants (aged 1.5 to $>65$ years), fifty-eight $(2 \cdot 7 \%)$ reported eating game birds. The mean intake in consumers was $19 \cdot 5$ (SD $18 \cdot 1$ ) $\mathrm{g} / \mathrm{d}$ (median $15 \cdot 6$, range $1 \cdot 3-92 \cdot 9 \mathrm{~g} / \mathrm{d}$; 95th centile $51 \cdot 7,97 \cdot 5$ th centile $84 \cdot 8 \mathrm{~g} / \mathrm{d}$ ). A greater proportion of female than male participants ate game birds (30/1119 (2.7\%) v. 21/1007 (2.1\%), respectively), but the difference was not statistically significant ( $\chi^{2}$ test, $P=0 \cdot 370$, NS). A greater proportion of adults ( $\geq 19$ years old) ate game birds than children $(1 \cdot 5-18$ years old; $35 / 1031(3 \cdot 4 \%)$ v. 16/1095 (1.5\%), respectively; $\chi^{2}$ test, $\left.P=0 \cdot 004\right)$. The highest prevalence of consumption was recorded in adults aged 19-64 years (34/813 (4.2\%); ANOVA for effect of age group on game bird consumption (yes/no), $P=0 \cdot 006$ ), but the greatest intakes $(\mathrm{g} / \mathrm{d})$ were reported in those aged $\leq 65$ years, although not significantly so (ANOVA for effect of age group on intake of game birds in game bird consumers, $P=0 \cdot 224$, NS; Table 1 ). Consumption of game bird meat as a proportion of total meat intake was greatest in those aged $\geq 65$ years, but this was not statistically significant (ANOVA for effect of age group on game birds as proportion of total meat intake in game bird consumers, $P=0 \cdot 406$, NS; Table 1 ).

It was not possible to analyse data specifically for pregnant women as they are excluded from the NDNS. In women of childbearing age ( $15-45$ years), 11/383 (2.9\%) reported eating game birds, with a mean intake of $22 \cdot 4$ (sD $25 \cdot 8$ ) g/d (median $15 \cdot 6$, range $2 \cdot 0-92 \cdot 9 \mathrm{~g} / \mathrm{d}$ ). In children aged $\leq 6$ years, $3 / 342(0.9 \%)$ were reported to have eaten game birds, with a mean intake of $6 \cdot 8(\mathrm{SD} 9 \cdot 7) \mathrm{g} / \mathrm{d}$ (median $2 \cdot 4$, range $1 \cdot 3-23 \cdot 2 \mathrm{~g} / \mathrm{d}$ ).

There was no difference in the prevalence of consumption according to whether it was in the shooting season or not (Table $2 ; \chi^{2}$ test, $P=0 \cdot 516$, NS). The prevalence of game bird consumption was greatest in the south of England (including London; ANOVA for effect of region on game bird consumption (yes/no), $P=0 \cdot 003$; Table 3).

There were no statistically significant associations with education, housing tenure, type of shop used, shopping
Table 2 Prevalence of game bird consumption according to shooting season for game birds in the UK (NDNS 2008-2010; $n 2126$, participants aged 1.5 to $>65$ years)

\begin{tabular}{llllll}
\hline & \multicolumn{4}{c}{ Eat game birds } \\
\cline { 2 - 3 } \cline { 5 - 6 } & \multicolumn{2}{c}{ Yes } & & \multicolumn{2}{c}{ No } \\
\cline { 2 - 3 } \cline { 5 - 6 } & $n$ & $\%$ & & $n$ & $\%$ \\
\hline Shooting season & & & & \\
Yes (August-February) & 31 & $54 \cdot 4$ & & 1179 & $58 \cdot 7$ \\
No (March-July) & 26 & $45 \cdot 6$ & & 830 & $41 \cdot 3$ \\
\hline
\end{tabular}

NDNS, National Diet and Nutrition Survey.

$\chi^{2}$ test for effect of shooting season $v$. not shooting season on game bird consumption (yes/no), $P=0.516$ (NS).

Table 3 Prevalence of game bird consumption in six regions of the UK (NDNS 2008-2010; $n 2126$, participants aged 1.5 to $>65$ years)

\begin{tabular}{|c|c|c|c|c|}
\hline \multirow[b]{3}{*}{ Region } & \multicolumn{4}{|c|}{ Eat game birds } \\
\hline & \multicolumn{2}{|c|}{ Yes } & \multicolumn{2}{|c|}{ No } \\
\hline & $n$ & $\%$ & $n$ & $\%$ \\
\hline England: North & 7 & $11 \cdot 9$ & 500 & $24 \cdot 2$ \\
\hline England: Central/Midlands & 3 & $5 \cdot 1$ & 340 & $16 \cdot 4$ \\
\hline England: South (including London) & 38 & $64 \cdot 4$ & 895 & $43 \cdot 3$ \\
\hline Scotland & 8 & $13 \cdot 6$ & 168 & $8 \cdot 1$ \\
\hline Wales & 3 & $5 \cdot 1$ & 100 & $4 \cdot 8$ \\
\hline Northern Ireland & 0 & 0 & 65 & $3 \cdot 1$ \\
\hline
\end{tabular}

NDNS, National Diet and Nutrition Survey.

ANOVA for effect of region on game bird consumption (yes/no), $P=0.003$.

at an independent butchers, buying organic, buying organic meat, self-assessed general health or ethnicity on reported game bird consumption $\left(\chi^{2}\right.$ test, all $P>0 \cdot 05$, NS; data not shown).

\section{Discussion}

It is known that $\mathrm{Pb}$ gunshot pellets can fragment upon impact; these fragments remain in the meat and are thus ingested, even though larger particles are removed ${ }^{(3)}$. In the study of Pain et $a l .{ }^{(3)}$, a large proportion of the game birds in the UK had Pb levels that exceeded the European 
Union maximum level of $0 \cdot 1 \mathrm{mg} / \mathrm{kg}$ wet weight for meat of bovine animals, sheep, pigs and poultry. It was recognised, however, that bioavailability may be lower than from endogenous $\mathrm{Pb}$. They calculated that high intakes of some types of game birds could result in the current FAO/WHO Provisional Weekly Tolerable Intake of $\mathrm{Pb}^{(16)}$ for adults being exceeded. They noted that this might be of particular concern for children and those eating large amounts of game. In a further analysis, Pain and Green used UK food consumption and $\mathrm{Pb}$ concentration data to estimate the potential health risks of game bird consumption. They found that consumption of $<1$ game bird meal per week may be associated with a 1-point deficit in intelligence quotient in children, and that consumption of 1.2-6.5 game bird meals per week may be associated with adverse health effects in adults, including effects on systolic blood pressure, and the rates of chronic kidney disease and miscarriage $^{(8)}$. Thus even quite modest intakes of $\mathrm{Pb}$-shot game birds could have adverse health effects. However, there are no published data, to our knowledge, on game bird consumption in the UK in pregnant women and children. We have used the best and most recently available data in the UK (NDNS 2008-2010) to determine game bird consumption in the general population and in two vulnerable groups: women of childbearing age (15-45 years old) and children $\leq 6$ years old.

The prevalence of people consuming game birds in the total UK NDNS sample was low $(2 \cdot 7 \%)$, and intakes (range $1 \cdot 3-92 \cdot 9 \mathrm{~g} / \mathrm{d}$ ) were also low. Standard portion sizes for game bird meat in adults range from $115 \mathrm{~g}$ for pigeon to $430 \mathrm{~g}$ for pheasant (meat only, no bones) ${ }^{(17)}$, implying that the diet diary had recorded one game meal only in the $4 \mathrm{~d}$. The values for the whole sample were very similar to those in women of childbearing age (prevalence of consumption $2 \cdot 9 \%$, intake range $2 \cdot 0-92 \cdot 9 \mathrm{~g} / \mathrm{d}$ ). Although this gives little cause for concern in the sample as a whole, any exposure to $\mathrm{Pb}$ in pregnancy should be avoided as this is the only way to minimise in utero transfer of $\mathrm{Pb}$. The prevalence of consumption in children $\leq 6$ years old was much lower $(0 \cdot 9 \%)$ and the maximum intake was very small $(23 \cdot 2 \mathrm{~g} / \mathrm{d})$. This is unlikely to contribute greatly to these children's dietary intake of $\mathrm{Pb}$. However, as there is no safe lower limit for blood $\mathrm{Pb}$ levels, and adverse effects have been reported at levels previously considered as being of little concern $^{(18)}$, exposure in children should be minimised.

As game bird meat is relatively expensive ${ }^{(7)}$ and was not readily available in supermarkets until recently, we expected that participants of higher educational attainment (reflecting social class) would have a greater prevalence of game bird consumption, but this was not the case. This finding was reinforced by the lack of an effect of housing tenure, type of shop used, shopping at independent butchers, buying organic, buying organic meat, self-assessed general health or ethnicity. It may be that the sample was not large enough to show an effect. However, consumption is known to be high among those who shoot regularly or are associated with shooting ${ }^{(19)}$. It is estimated that $14 \%$ of all game shot in the UK is given away to guns (shooters) and to beaters (employed to walk though woods or over moors and fields to drive game towards the guns) and other shoot employees ${ }^{(20)}$ (these birds are often those that are too badly damaged for sale and may contain more $\mathrm{Pb}$ than undamaged birds ${ }^{(3)}$ ). It was not possible to determine the representation of this group in the sample, but they would be an important group to monitor in future studies.

There was no effect of shooting seasonality on game bird consumption. Shooting seasons vary slightly for different types of birds (for example: pheasant, 1 October-1 February; partridge, 1 September-1 February; grouse, 12 August-10 December). It could be that storage of game birds in freezers and year-round availability in supermarkets erode seasonal effects.

Game bird consumption was most frequent in the south of England, perhaps due to more ready availability in supermarkets and a wider range of shops. The second two most frequent areas were the north of England and Scotland: these are areas in which game bird shooting is popular and so local consumption would be expected to be relatively higher.

There are several limitations to the current study. Caution must be exercised in the use of the $4 \mathrm{~d}$ diet diary to assess the consumption of foods that are eaten relatively infrequently, such as game birds. If the data were combined with an FFQ, it would be possible to use statistical analysis tools such as the Multiple Source Method to quantify usual distributions of intake. It is possible that the consumption of game birds has increased since the 2008-2010 NDNS, with wider availability in supermarkets and promotion of the health benefits and ethical aspects of eating game, and so the data reported here may not reflect current consumption. In addition, we were not able to tell if the game birds were $\mathrm{Pb}$-shot or had been farmed. Finally, although the sample is representative of the UK population, a larger sample would enable greater confidence in data obtained from subgroups and their statistical analyses.

Further work should be undertaken to study $\mathrm{Pb}$ intakes from game birds and other foods in a larger group of pregnant women and children; diet diaries may not be suitable for this purpose. Trends in consumption of game birds in these groups should be monitored. Other groups who are likely to be eating game birds frequently, such as gamekeepers and employees on game shoots and their families, should also be monitored.

\section{Conclusion}

The prevalence of consumption of game birds by women of childbearing age and children $\leq 6$ years old was relatively low and reported intakes were small. There are uncertainties 
about the ability of the NDNS to capture the consumption of food items that are infrequently consumed and this is likely to result in lower overall levels of reporting than in reality. Alternative methods of capturing these data should be used in future studies. Any exposure to $\mathrm{Pb}$ in these two vulnerable groups is undesirable, and it is possible that the prevalence of consumption may have risen in these two groups since the 2008-2010 NDNS.

\section{Acknowledgements}

Sources of funding: C.M.T. is supported by a Daphne Jackson Trust Fellowship sponsored by the University of Bristol. The NDNS was funded by the Department of Health. The original data creators, depositors or copyright holders, the funders of the Data Collections and the UK Data Archive bear no responsibility for their further analysis or interpretation. Conflicts of interest: The authors declare that they have no conflicts of interest associated with this manuscript. Authors' contributions: All authors contributed to the conception, design and interpretation of the study. All authors have approved the final version of the paper.

\section{References}

1. Delves HT (1998) International Studies on Trends in Blood Lead, and the Use of Lead Isotopes Ratios to Identify Environmental Sources. IEH Report on Recent UK Blood Lead Surveys. Report no. R9. pp. 40-52. Norwich: Medical Research Council/Insitute for Environment and Health.

2. European Food Safety Authority Panel on Contaminants in the Food Chain (2010) Scientific opinion on lead in food. EFSA J 8, 1570-1717.

3. Pain DJ, Cromie RL, Newth J et al. (2010) Potential hazard to human health from exposure to fragments of lead bullets and shot in the tissues of game animals. PLoS One 5, e10315.

4. Iqbal S, Blumenthal W, Kennedy C et al. (2009) Hunting with lead: association between blood lead levels and wild game consumption. Environ Res 109, 952-959.

5. Bjerregaard P, Johansen P, Mulvad G et al. (2004) Lead sources in human diet in Greenland. Environ Health Perspect 112, 1496-1498.

6. Countryside Alliance (not dated) Game-to-eat. Nutritional facts. http://www.gametoeat.co.uk/article/nutritional-facts (accessed October 2012).

7. Countryside Alliance (not dated) Game-to-eat. Supermarket spy: recent findings. http://www.gametoeat.co.uk/ supermarket-spy/recent-findings (accessed October 2012).

8. Green RE \& Pain DJ (2012) Potential health risks to adults and children in the UK for exposure to dietary lead in gamebirds shot with lead ammunition. Food Chem Toxicol 50, 4180-4190.
9. Food Standards Agency (2012) Advice to frequent eaters of game shot with lead. http://www.food.gov.uk/news-updates/ news/2012/oct/lead-shot (accessed October 2012).

10. Spanish Agency for Food Safety and Nutrition (2012) Report of the Scientific Committee of the Spanish Agency for Food Safety and Nutrition (AESAN) in relation to the risk associated with the prescence of lead in wild game meat in Spain. AEAS-2012-002 Report approved by the Scientific Committee on plenary session 22 February 2012. http://www.aesan.msc.es/AESAN/docs/docs/evaluacion_ riesgos/comite_cientifico/ingles/LEAD_GAME.pdf

11. Federal Insitute for Risk Assessment (2011) Lead fragments in game meat can be an added health risk for certain consumer groups. http://www.bfr.bund.de/en/press_ information/2011/32/lead_fragments_in_game_meat_can_ be_an_added_health_risk_for_certain_consumer_groups127610.html (accessed October 2012).

12. National Centre for Social Research, Medical Research Council. Resource Centre for Human Nutrition Research \& University College London. Medical School (2012) National Diet and Nutrition Survey, 2008-2010 (computer file), 3rd edition. Colchester, Essex: UK Data Archive (distributor), February 2012. SN: 6533, http://dx.doi.org/ 10.5255/UKDA-SN-6533-2

13. Whitton C, Nicholson SK, Roberts C et al. (2011) National Diet and Nutrition Survey: UK food consumption and nutrient intakes from the first year of the rolling programme and comparisons with previous surveys. Br J Nutr 106, 1899-1914.

14. Food Standards Agency \& Department of Health (2010) National Diet and Nutrition Survey. Headline results from Year 1 of the Rolling Programme (2008/9) [B Bates, A Lennox and G Swan, editors]. http://www.food.gov.uk/ multimedia/pdfs/publication/ndnsreport0809.pdf (accessed November 2012)

15. Tipping S (2010) Appendix B. Weighting the NDNS core sample. http://www.dh.gov.uk/prod_consum_dh/groups/ dh_digitalassets/documents/digitalasset/dh_130786.pdf (accessed November 2012).

16. World Health Organization (2007) Exposure to children of chemical hazards in food. http://www.euro.who. int/_data/assets/pdf_file/0003/97446/4.4.pdf (accessed October 2012).

17. Ministry of Agriculture Fisheries and Food (1993) Food Portion Sizes, 2nd ed. [H Crawley, editor]. London: The Stationery Office.

18. Chandramouli K, Steer C, Ellis M et al. (2009) Effects of early childhood lead exposure on academic performance and behaviour of school age children. Arch Dis Child $\mathbf{9 4}$, 844-848.

19. Food Standards Agency (2012) Habits and behaviours of highlevel consumers of lead-shot wild-game meat in Scotland. http://www.foodbase.org.uk//admintools/reportdocuments/ 776-1-1353_FS421005_Habits_and_behaviours_of_high-level_ consumers_of_lead-shot_wild-game_meat_in_Scotland_ FINAL.pdf (accessed October 2012).

20. Countryside Alliance (2004) Game-to-eat. New Game survey says - sell direct for success. http://www.epolitix. com/Resources/epolitix/Forum\%20Microsites/Countryside \%20Alliance/CA_280704.pdf (accessed October 2012). 